\title{
Proguanil and cycloguanil are organic cation transporter and multidrug and toxin extrusion substrates
}

\author{
Maarten van der Velden', Albert Bilos', Jeroen J. M. W. van den Heuvel', Sanna R. Rijpma', \\ Evelien G. E. Hurkmans' ${ }^{1}$, Robert W. Sauerwein ${ }^{2}$, Frans G. M. Russel ${ }^{1}$ and Jan B. Koenderink ${ }^{1 *}$
}

\begin{abstract}
Background: Malaria, HIV/AIDS, and tuberculosis endemic areas show considerable geographical overlap, leading to incidence of co-infections. This requires treatment with multiple drugs, potentially causing adverse drug-drug interactions (DDIs). As anti-malarials are generally positively charged at physiological pH, they are likely to interact with human organic cation transporters 1 and 2 (OCT1 and OCT2). These transporters are involved in the uptake of drugs into hepatocytes and proximal tubule cells for subsequent metabolic conversion or elimination. This efflux of cationic drugs from hepatocytes and proximal tubule cells into bile and urine can be mediated by multidrug and toxin extrusion 1 and 2-K (MATE1 and MATE2-K) transporters, respectively.
\end{abstract}

Methods: Here, the interaction of anti-malarials with these transporters was studied in order to predict potential DDIs. Using baculovirus-transduced HEK293 cells transiently expressing human OCT1, OCT2, MATE1 and MATE2K uptake and inhibition was studied by a range of anti-malarials.

Results: Amodiaquine, proguanil, pyrimethamine and quinine were the most potent inhibitors of 4-(4-(dimethylamino)styryl)-N-methylpyridinium iodide (ASP) transport, a known substrate of OCT1/2, resulting in half maximal inhibitory concentrations $\left(I C_{50}\right)$ of $11,13,1.6$, and $3.4 \mu \mathrm{M}$, respectively. Only quinine had a drug-drug index higher than the cut-off value of 0.1 for OCT2, therefore, in vivo pharmacokinetic studies focusing on DDIs involving this compound and other OCT2-interacting drugs are warranted. Furthermore, proguanil appeared to be a substrate of OCT1 and OCT2 with affinities of 8.1 and $9.0 \mu \mathrm{M}$, respectively. Additionally, MATE1 and MATE2-K were identified as putative transport proteins for proguanil. Finally, its metabolite cycloguanil was also identified as an OCT1, OCT2, MATE1 and MATE2-K substrate.

Conclusion: Anti-malarials can reduce OCT1 and OCT2 transport activity in vitro. Furthermore, proguanil and cycloguanil were found to be substrates of OCT1, OCT2, MATE1 and MATE2-K, highlighting the importance of these transporters in distribution and excretion. As these compounds shares substrate overlap with metformin DDIs can be anticipated during concurrent treatment.

Keywords: Proguanil, Cycloguanil, OCT1, OCT2, MATE1, MATE2-K, Anti-malarial, SLC

\section{Background}

In 2015, there were over 200 million cases of malaria, causing more than 400,000 deaths [1]. To treat

\footnotetext{
*Correspondence: Jan.Koenderink@radboudumc.nl

1 Department of Pharmacology and Toxicology, Radboud University

Medical Center, Geert Grooteplein 28, 6525 GA Nijmegen, The

Netherlands

Full list of author information is available at the end of the article
}

uncomplicated malaria infections, the World Health Organization (WHO) recommends the use of artemisinin-based combination therapy (ACT), consisting of an artemisinin-derivative and partner drug that has a longer half-life [2]. The use of a variety of different drugs, like anti-malarials taken during pregnancy or for prophylaxis or Plasmodium vivax relapse prevention, creates a substantial pool of drugs. Considering the 
geographical overlap with HIV/AIDS and tuberculosis (TB), co-infections could occur. As there are multiple anti-retrovirals (ARV), anti-TB and anti-malarials available for treatment, there is considerable risk for adverse drug-drug interactions (DDIs) if used concomitantly. These DDIs might lead to under- or overexposure of coadministered drugs potentially causing either treatment failure or toxicity. Although DDIs between current cotreatment of HIV and malaria have been predicted to be low [3], recent studies showed altered anti-malarial plasma concentrations upon ARV treatment [4-6]. Little is known about the potential interaction between antimalarials and the anti-TB drugs rifampicin and rifabutin [7], although it has been shown that rifampicin increases the clearance of quinine [8].

DDIs frequently occur at the level of biotransformation by cytochrome P450 enzymes in the liver [9], but membrane transport proteins can also be involved [10]. Previously, the potential treatment implications due to possible competition of anti-malarial and antiretroviral DDIs for cellular efflux via ATP binding cassette (ABC) transporters was brought forward [11]. Here, the interaction with organic cation transporters was studied, as anti-malarials are positively charged at physiological $\mathrm{pH}$. Transport proteins belonging to the solute carrier (SLC) family are important for the elimination of drugs, contain members that mainly import cations and have been linked to DDIs. Organic cation transporters (OCT) 1 and OCT2 are cellular uptake transporters belonging to the solute carrier (SLC) family, which are mainly expressed in liver and kidney [12] and within these organs localize to the basolateral membrane of hepatocyte and proximal tubule cells, respectively $[13,14]$. Other important SLCs implicated in the transport of cationic drugs are multidrug and toxin extrusion (MATE) protein 1 and MATE2-K. They are primarily located to the apical side of proximal tubule cells (both) $[15,16]$ and hepatocytes (MATE1) [15], where they export drugs into the urine and bile, respectively. As OCT and MATE transporters are important for the cellular uptake and export of drugs, interaction with these transporters could lead to unwanted adverse effects. Therefore, it is important to address interactions of anti-malarials with these transporters, in order to avoid potential drug-drug interactions in future therapy.

The inhibitory potential of eleven anti-malarials (amodiaquine, artemisinin, atovaquone, chloroquine, dihydroartemisinin, lumefantrine, mefloquine, primaquine, proguanil, pyrimethamine, and quinine) on human OCT1 and OCT2 transport activity was studied using HEK293 cells, in which these transporters were overexpressed by baculovirus transduction. Anti-malarials $(25-50 \mu \mathrm{M})$ that inhibited transport activity by more than $67 \%$ were selected for further determination of their half maximal inhibitory concentration $\left(\mathrm{IC}_{50}\right)$. Furthermore, it was determined which anti-malarials are potential OCT1 or OCT2 substrates and whether MATE1 or MATE2-K could play a role in the cellular efflux of these substrates.

\section{Methods \\ Materials}

Human embryonic kidney (HEK293) cells transiently expressing (a combination of) human transporters of interest [organic cation transporter 1 or 2 (OCT1; SLC22A1 or OCT2; SLC22A2), multidrug and toxin extrusion protein 1 or $2-\mathrm{K}$ (MATE1; SLC47A1 or MATE2-K; SLC47A2)], or enhanced yellow fluorescent protein (eYFP) were obtained from PharmTox (Nijmegen, The Netherlands).

BioCoat poly-D-lysine coated 24- and 96-wells plates were purchased from Becton-Dickinson B.V. (Breda, The Netherlands). Dulbecco's Modified Eagle's Medium (DMEM) + GlutaMAX-I, Hank's balanced salt solution (HBSS) and 4-(4-(dimethylamino)styryl)- $N$-methylpyridinium iodide (ASP; $\geq 95 \%$ purity) were purchased from Life Technologies Europe B.V. (Bleiswijk, The Netherlands). Fetal bovine serum was purchased from Greiner Bio-One B.V. (Alphen a/d Rijn, The Netherlands). Sodium butyrate, amodiaquine dihydrochloride dehydrate (AQ; analytical standard), artemisinin (ART; 98\% purity), atovaquone (ATO; $\geq 98 \%$ purity), chloroquine diphosphate (CQ; $\geq 98 \%$ purity), dihydroartemisinin (DHA; $\geq 97 \%$ purity), lumefantrine (LUM; $\geq 98 \%$ purity), mefloquine hydrochloride (MQ; $\geq 98 \%$ purity), primaquine diphosphate (PQ; $98 \%$ purity), proguanil hydrochloride (PG; $\geq 95 \%$ purity), pyrimethamine (PYR; $98.8 \%$ purity), quinine (QN; $\geq 98 \%$ purity) and 4-(2-hydroxyethyl)-1-piperazineethanesulfonic acid (HEPES) were purchased from Sigma-Aldrich Chemie B.V. (Zwijndrecht, The Netherlands). Cycloguanil (CG; 95\% purity) was purchased from Aurum Pharmatech (Franklin Park, NJ, United States). N-methyl-quinidine (NMQ) was purchased from Solvo Biotechnology (Szeged, Hungary). Bovine serum albumin fraction V (BSA) was purchased from Roche Diagnostics Nederland B.V. (Almere, The Netherlands). The Victor X3 multimode plate reader was purchased from PerkinElmer Nederland B.V. (Groningen, The Netherlands). Bio-Rad protein assay was purchased from Bio-Rad laboratories Inc. (Veenendaal, The Netherlands). The acquity ultra performance liquid chromatography (UPLC) and Xevo TQ-S micro mass spectrometer was purchased from Waters (Milford, MA, USA). Finally, the HSS T3 analytical column and VanGuard HSS T3 pre-column were purchased from Waters (Dublin, Ireland). 


\section{HEK293 cell culture and transduction}

HEK293 cells were modified to transiently express (a combination of) human OCT1, OCT2, MATE1, MATE2-K, or eYFP. Briefly, cDNA of the respective genes was cloned downstream of a CMV promoter into a baculovirus, of which passage three was used to transduce HEK293 cells. These cells were seeded in poly-D-lysine coated 24- or 96-wells plates and grown in a $37{ }^{\circ} \mathrm{C}$ incubator at $5 \% \mathrm{CO}_{2}$. Growth was initiated at $\sim 25 \%$ confluency using 375 or $125 \mu \mathrm{L}$ cell and complete medium (DMEM + GlutaMAX ${ }^{\mathrm{TM}}$-I supplemented with $10 \%$ fetal bovine serum) suspension per well, respectively. After $24 \mathrm{~h}$, cells were transduced with $30 \mu \mathrm{L}$ virus $(10 \mu \mathrm{L}$ virus $+20 \mu \mathrm{L}$ complete medium in case of 96-wells plates) or $2 \times 15 \mu \mathrm{L}$ virus for cells that required simultaneous expression of two transporters. Finally, $195 \mu \mathrm{L}$ sodium butyrate ( $45 \mu \mathrm{L}$ for 96 -wells plates) was added to a final concentration of $2 \mathrm{mM}$ to enhance protein expression [17].

\section{Cellular transport inhibition assays}

AMO (10 mM), ASP (1 mM), CQ (10 mM), PQ (10 mM) and PG $(10 \mathrm{mM})$ were dissolved in MilliQ water. ART (10 mM), ATO (10 mM), DHA (10 mM), LUM (10 mM), MQ (10 mM), NMQ (20 mM), PYR (10 mM), QN $(10 \mathrm{mM})$ were dissolved in DMSO. All compound stocks were stored at $-20{ }^{\circ} \mathrm{C}$. Inhibition of OCT1- or OCT2mediated ASP uptake by anti-malarials was performed in poly-D-lysine coated 96-wells plates 2 or 3 days following HEK293 cell transduction. In short, cells were washed with $125 \mu \mathrm{L} 37^{\circ} \mathrm{C}$ HBSS containing $10 \mathrm{mM}$ HEPES, pH 7.4. Then, a $50 \mu \mathrm{L}$ mixture of ASP $(10 \mu \mathrm{M})$ and antimalarial compound $(25,50$ or $100 \mu \mathrm{M})$ in HBSS buffer ( $\mathrm{pH}$ 7.4) was added to each well and incubated for $10 \mathrm{~min}$ at $37{ }^{\circ} \mathrm{C}$. ASP transport was stopped by washing with $125 \mu \mathrm{L}$ ice-cold HBSS-HEPES buffer supplemented with $0.5 \%$ BSA. Following a second wash with $125 \mu \mathrm{L}$ ice-cold HBSS-HEPES buffer, cells were lysed with $125 \mu \mathrm{L} 1 \mathrm{M}$ $\mathrm{NaOH}$ and ASP was excited at a wavelength of $485 \mathrm{~nm}$ and fluorescence was detected at an emission wavelength of $535 \mathrm{~nm}$ using the Victor X3 multimode plate reader. Anti-malarial inhibition of OCT1- or OCT2-mediated ASP uptake was corrected for background signal (eYFPtransduced cells; mock-transduced), normalized to protein content using the Bio-Rad protein assay and represented as relative ASP uptake after fixing solvent controls to $100 \%$. The mean \pm standard error of the mean (SEM) of three independent experiments performed in triplicate were plotted in GraphPad Prism version 5.03 (GraphPad Software, Inc., La Jolla, CA, USA) and significantly reduced ASP uptake was determined using a oneway ANOVA with Dunnett's post test.
Concentration-dependent inhibition was assessed of anti-malarial compounds that inhibited ASP uptake by more than $67 \%$ in the initial screens. For each compound, a range of seven concentrations was used to determine the concentration at which ASP uptake was inhibited half maximally $\left(\mathrm{IC}_{50}\right)$. At least three independent experiments (4 for QN) were performed for each drug in triplicate as described above. Inhibition curves were plotted by nonlinear regression analyses of the data using GraphPad Prism version 5.03. Minimum uptake was set to be greater than $0 \%$ and the curve-fitted top within each experiment was adjusted to $100 \%$ as follows: each uptake percentage value was multiplied by $100 /$ top in order to let the curve fit start at $100 \%$ at the lowest drug concentration. To generate the final dose-response inhibition curve per anti-malarial, percentage of uptake was averaged for each drug concentration per experiment and the resulting mean \pm SEM corresponding to three or four independent experiments were plotted.

\section{DDI index calculation}

In order to predict whether future pharmacokinetic studies are recommended to study transporter inhibition in vivo, DDI indices were calculated by using the formula DDI index $=$ fraction unbound ${ }^{*} \mathrm{C}_{\max } / \mathrm{IC}_{50}$ with a cut-off value of 0.1 [18]. As $C_{\max }$ the (geometric) mean or median maximum plasma concentrations obtained from previous in vivo pharmacokinetic studies after therapeutic dosing was used.

\section{Cellular import and export assays}

HEK293 cells were seeded in 24-wells poly-D-lysine coated plates and transduced the subsequent day with OCT1 or OCT2 as described above. Three days following transduction, OCT1- or OCT2-mediated uptake of ten anti-malarials (AMO, ART, ATO, CQ, DHA, LUM, MQ, PQ, PG, and QN) was performed. NMQ served as a positive substrate for both OCT1 and OCT2 import [19]. In short, cells were washed with $400 \mu \mathrm{L} 37^{\circ} \mathrm{C}$ HBSSHEPES buffer followed by adding $150 \mu \mathrm{L}$ HBSS buffer with $10 \mu \mathrm{M}$ anti-malarial or NMQ to each well. After incubation for $15 \mathrm{~min}$ at $37{ }^{\circ} \mathrm{C}$, import was stopped by washing with $400 \mu \mathrm{L}$ ice-cold HBSS-HEPES buffer supplemented with $0.5 \%$ BSA. Following a second wash with $400 \mu \mathrm{L}$ ice-cold HBSS-HEPES buffer, cells were lysed with $200 \mu \mathrm{L} 50 \%(\mathrm{v} / \mathrm{v}) \mathrm{MeOH}$ and $0.1 \%(\mathrm{v} / \mathrm{v})$ formic acid $(\mathrm{HCOOH})$ in water and samples were sent for quantification by mass spectrometry analysis (see "LC-MS/MS quantification of anti-malarials" section). Anti-malarial import mediated by OCT1 or OCT 2 was performed in two independent experiments in triplicate per drug and normalized to background (mock-transduced cells). 
Percentage of anti-malarial uptake (compared to background control) was plotted as mean (6 values) \pm SEM in GraphPad Prism version 5.03 and drugs with at least a twofold increase versus background were selected for further analysis.

The affinity $\left(\mathrm{K}_{\mathrm{M}}\right)$ and maximum transport rate $\left(\mathrm{V}_{\max }\right)$ for OCT1 and OCT2 of PG were determined by analysing concentration-dependent uptake data from three independent experiments. The experimental setup was similar to the cellular import assay, except that a range of four concentrations (2.0, 3.9, 7.8 and $16 \mu \mathrm{M})$ and an incubation time of 1 min was used to determine the $K_{M}$ of proguanil. The Michaelis-Menten curve was plotted as mean \pm SEM in GraphPad version 5.03 after fixing the $\mathrm{V}_{\max }$ of each individual experiment to $100 \%$ and subtracting mock-transduced background for each concentration used.

Import and export of PG and cycloguanil (CG) was assessed by single and double transduced HEK293 cells. In short, HEK293 cells seeded in 24-wells plates as described, were transduced separately with eYFP, OCT1, OCT2, MATE1 or MATE2-K, or with combinations of these viruses. Following the same procedure as for the cellular import assay described above, the import of $100 \mu \mathrm{M}$ PG and CG was measured after 5 min incubation and data was plotted as mean $\mathrm{pmol} / \mathrm{mg} / \mathrm{min} \pm$ SEM. For export (following OCT1 uptake) of $1 \mu \mathrm{M}$ PG after 1 min of transport at $\mathrm{pH} 7.4$, percentage of remaining cellular PG (compared to background) was plotted as mean \pm SEM in GraphPad version 5.03. Significant reduction in uptake (i.e. export by MATEs) was determined using $\ln$ transformation and a one-way repeated measures ANOVA with Dunnet's post test.

\section{Liquid chromatography-tandem mass spectrometry (LC-} MS/MS) quantification of anti-malarials

Anti-malarial concentration in the cell lysates was quantified using an LC-MS/MS system consisting of a UPLC, a binary solvent manager, a vacuum degasser and an autosampler, coupled to a Xevo TQ-S micro triple quadrupole mass spectrometer. Liquid chromatographic separation of the samples (stored at $10{ }^{\circ} \mathrm{C}$; injection volume of $10 \mu \mathrm{L}$ ) was performed at $40{ }^{\circ} \mathrm{C}$ using a HSS T3 analytical column $(1.8 \mu \mathrm{m} ; 100 \times 2.1 \mathrm{~mm})$ coupled to a VanGuard HSS T3 pre-column $(1.8 \mu \mathrm{m} ; 5 \times 2.1 \mathrm{~mm})$. The mobile phase (run time: $10 \mathrm{~min}$ ) consisted of solvent $\mathrm{A}$ [ $20 \mathrm{mM}$ ammonium formate and $0.5 \%(\mathrm{v} / \mathrm{v})$ formic acid $(\mathrm{HCOOH})$ in water] and solvent $\mathrm{B}[0.5 \%(\mathrm{v} / \mathrm{v})$ formic acid $(\mathrm{HCOOH})$ in acetonitrile] using the following gradient with a flow of $200 \mu \mathrm{L} / \mathrm{min}$ : $0-0.5 \mathrm{~min}, 50 \%$ A; $0.5-4.5 \mathrm{~min}, 5 \%$ A; $4.5-10 \mathrm{~min}, 50 \%$ A. Electrospray ionization (ESI) was operated at a capillary voltage of $+1.0 \mathrm{kV}$ and desolvation and source temperatures of 600 and $150{ }^{\circ} \mathrm{C}$, respectively. Nitrogen was used as desolvation gas with a gas flow of $1000 \mathrm{~L} / \mathrm{h}$. Argon was used as collision gas at a pressure of 1.5 mTorr. Positive ion mode was used with selected reaction monitoring (SRM) for the quantitative analysis of AMO, ART, ATO, CQ, CG, DHA, LUM, MQ, PQ, PG, and QN. The peak area of the most abundant product ion was used for quantification. Ions with their corresponding mass/charge $(\mathrm{m} / \mathrm{z})$ ratio are shown in Table 1.

\section{Results \\ Inhibition of OCT1- and OCT2-mediated ASP transport by anti-malarials}

Using the baculovirus transduction system as described previously [11], OCT1 and OCT2 were transiently expressed in HEK293 cells. These cells were used to study the inhibitory effect of eleven anti-malarials (AMO, ART, ATO, CQ, DHA, LUM, MQ, PQ, PG, PYR, and $\mathrm{QN}$ ) on OCT1- and OCT2-mediated ASP transport. Uptake of ASP by mock-transduced cells served as a negative control, which was used for background correction. Simultaneous incubation of $10 \mu \mathrm{M}$ ASP, a known substrate of OCT1 [20] and OCT2 [21], and $50 \mu \mathrm{M}$ antimalarial drug ( $25 \mu \mathrm{M}$ ATO and LUM, due to precipitation beyond these concentrations; $100 \mu \mathrm{M}$ QN was used as positive control) for $10 \mathrm{~min}$ at $37^{\circ} \mathrm{C}$ resulted in different inhibition profiles for OCT1 and OCT2. OCT1mediated ASP transport in HEK293-transduced cells was only partially inhibited to $49 \pm 3 \%$ by $100 \mu \mathrm{M}$ QN $(\mathrm{p}<0.05)$ and even stimulated by MQ to $150 \pm 21 \%$ $(\mathrm{p}<0.05)$ (Fig. 1a). Four other anti-malarials, AQ, PQ, PG, and PYR inhibited ASP uptake at a concentration of $50 \mu \mathrm{M}$ for more than $30 \%$, to a relative uptake of $67 \pm 4$, $59 \pm 3,60 \pm 7$, and $59 \pm 6 \%$, respectively, although these were non-significant inhibitions. In OCT2-transduced

Table 1 Mass fragments of the most abundant ions for the detection of anti-malarials by LC-MS/MS

\begin{tabular}{lll}
\hline Compound name & Precursor ion $(\mathbf{m} / \mathbf{z})$ & Product ion $(\mathbf{m} / \mathbf{z})$ \\
\hline Amodiaquine & 356.1 & 283.0 \\
Artemisinin & 282.0 & 162.9 \\
Atovaquone & 365.0 & 337.0 \\
Chloroquine & 320.1 & 247.1 \\
Cycloguanil & 252.1 & 58.0 \\
Dihydroartemisinin & 221.0 & 163.1 \\
Lumefantrine & 530.1 & 512.1 \\
Mefloquine & 379.1 & 361.1 \\
N-Methyl-quinidine & 339.1 & 160.0 \\
Primaquine & 260.1 & 243.1 \\
Proguanil & 254.0 & 170.0 \\
Quinine & 325.1 & 307.1
\end{tabular}




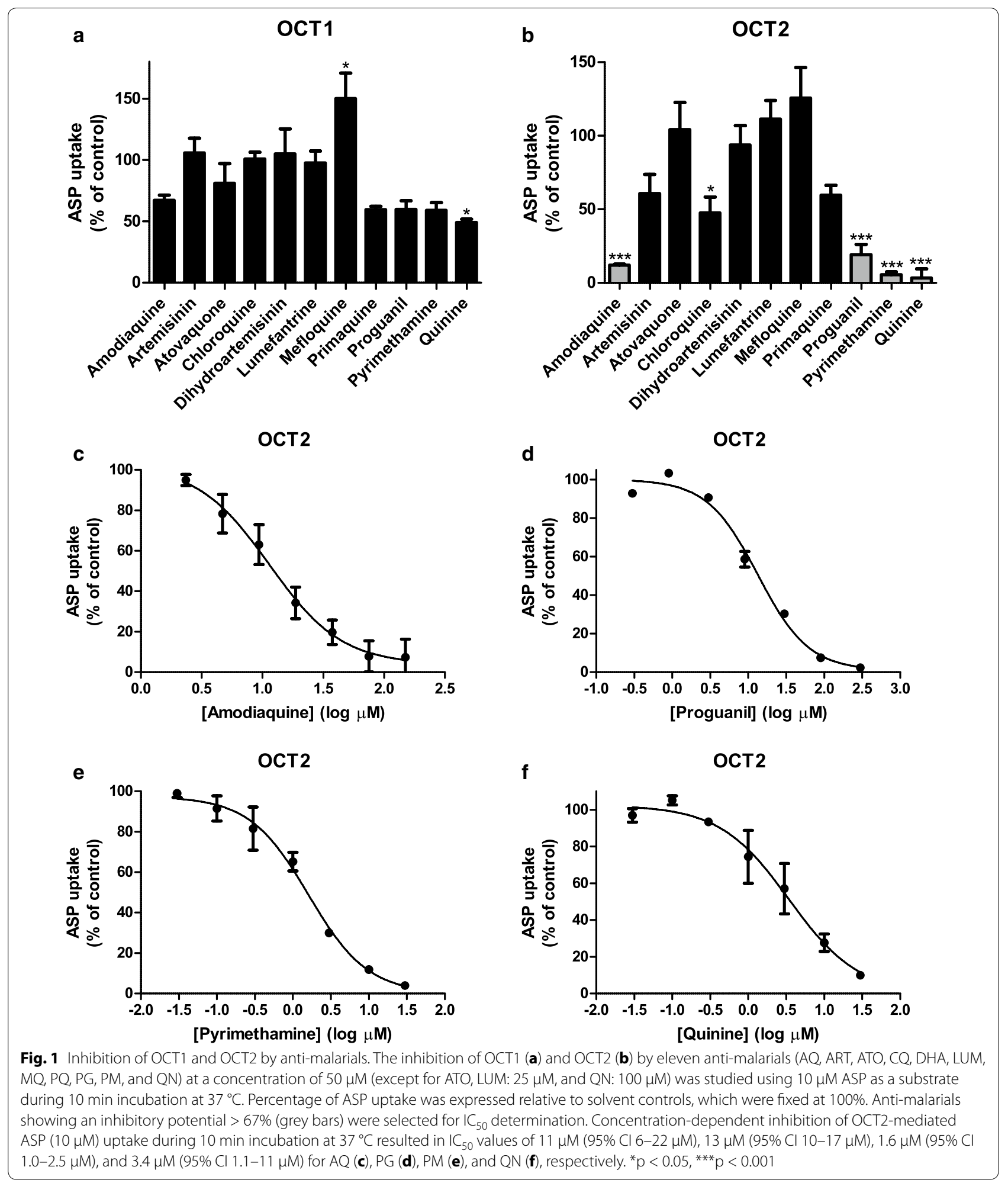

HEK293 cells, ASP uptake was reduced to $61 \pm 13$ and $60 \pm 7 \%$ by ART and PQ, respectively. AQ, CQ, PG, PYR, and QN significantly reduced ASP uptake to $12.1 \pm 0.6 \%$ (p < 0.001), $48 \pm 11 \%(\mathrm{p}<0.05), 19 \pm 7 \%(\mathrm{p}<0.001)$, $6 \pm 2 \%(\mathrm{p}<0.001)$, and $3 \pm 6 \%(\mathrm{p}<0.001)$, respectively (Fig. 1b). 
The anti-malarials that most potently inhibited OCT1and/or OCT2-mediated ASP import (more than 67\%) were selected for further analysis by determining their $\mathrm{IC}_{50}$-values. Using a larger concentration range, inhibition of OCT2-mediated transport of $10 \mu \mathrm{M}$ ASP by AQ, PG, PYR, and QN was assessed using a similar set-up as above. Sigmoidal inhibition curves were generated by plotting ASP uptake rates as percentage of control versus increasing drug concentrations (Fig. 1c-f). This resulted in the strongest inhibition by PYR and QN with low micromolar $\mathrm{IC}_{50}$ concentrations of $1.6 \mu \mathrm{M}$ (95\% CI 1.0$2.5 \mu \mathrm{M})$ and $3.4 \mu \mathrm{M}(95 \% \mathrm{CI} 1.1-11 \mu \mathrm{M})$, respectively. These were closely followed by $\mathrm{IC}_{50}$-concentrations of $11 \mu \mathrm{M}(95 \% \mathrm{CI} 6-22 \mu \mathrm{M})$ and $13 \mu \mathrm{M}(95 \% \mathrm{CI} 10-17 \mu \mathrm{M})$ for AQ and PG, respectively. In order to assess the clinical relevance of these values, DDI indices were calculated, and a cut-off value of 0.1 was applied to indicate the requirement for future in vivo pharmacokinetic studies [18]. Based on reported $C_{\max }$ and unbound fraction values, only QN, with a DDI index of 1.1, fulfilled the criterion (Table 2).

\section{OCT1- and OCT2-mediated proguanil and cycloguanil uptake}

Next, the potential substrates of OCT1 or OCT2 amongst the tested anti-malarials (AMO, ART, ATO, CQ, DHA, LUM, MQ, PQ, PG, and QN) were identified. Uptake of anti-malarials $(10 \mu \mathrm{M})$ in HEK293 cells expressing these transporters was determined following $15 \mathrm{~min}$ incubation at $37^{\circ} \mathrm{C}$ by LC-MS/MS after cell lysis. Uptake was represented as percentage of mocktransduced HEK293 control cells. Anti-malarials with more than twofold increase in uptake of control versus transporter cells were regarded as potential substrates. NMQ was used as a positive OCT1 and OCT2 control substrate. NMQ was taken up by OCT1 and OCT2 as expected. Only one anti-malarial, PG, showed an uptake of more than $200 \%$ of the control value. PG was taken up by OCT1 (301 $\pm 25 \%$ of control) as well as OCT2 $(207 \pm 17 \%)$ into HEK293 cells (Fig. 2a, b).

Next, the transport kinetics of PG uptake by OCT1 and OCT2 (eYFP-transduced cells served as background control) were studied. Concentration-dependent uptake of PG was measured during $1 \mathrm{~min}$ of incubation at $37^{\circ} \mathrm{C}$ and its affinity $\left(\mathrm{K}_{\mathrm{M}}\right)$ and maximum transport rate $\left(\mathrm{V}_{\text {max }}\right)$ were determined. Uptake of PG by OCT1 was characterized by a $\mathrm{K}_{\mathrm{M}}$ of $8.1 \pm 1.6 \mu \mathrm{M}$ and $\mathrm{V}_{\max }$ of $1840 \pm 510 \mathrm{pmol} /$ $\mathrm{mg}$ protein/min. PG affinity for OCT2 was similar with a $K_{M}$ of $9.0 \pm 1.1 \mu \mathrm{M}$ and $V_{\max }$ of $4440 \pm 1500 \mathrm{pmol} / \mathrm{mg}$ protein/min (Fig. 2c, d).

As PG is metabolized in the liver to its active metabolite CG by CYP2C19 [22], CG transport by OCT1 or OCT2 was investigated. Uptake studies of CG were performed similarly as with the previous anti-malarials, with a 5 min incubation time at $37{ }^{\circ} \mathrm{C}$. This resulted in significant uptake by OCT1 and OCT2 into HEK 293 cells (Fig. 2e).

\section{MATE1 and MATE2-K-mediated proguanil and cycloguanil transport}

As PG is likely imported into hepatocytes and proximal tubule cells via OCT1 and OCT2, it was tested whether this compound could be exported by the extrusion transporters MATE1 and MATE2-K. These transporters are able to export and import compounds depending on the physiological conditions. For this purpose, HEK293 cells were transduced with eYFP (mock), MATE1, or MATE2$\mathrm{K}$. Uptake was represented as percentage of eYFP control cells. Incubation of $100 \mu \mathrm{M}$ PG for 5 min resulted in small significant uptake by MATE1 (Fig. 3a).

To study PG export capacity of MATE1 and MATE2K, HEK293 cells were co-transduced with eYFP (mock)

Table 2 Calculated DDI indices of the four most potent OCT2 inhibitors

\begin{tabular}{|c|c|c|c|c|c|}
\hline Compound name & $C_{\max }(\mathrm{ng} / \mathrm{mL})^{\mathrm{a}}$ & $C_{\max }(\mu M)$ & Unbound fraction & $\mathrm{IC}_{50}(\mu \mathrm{M})$ & DDI index \\
\hline Amodiaquine & $5.2^{c}[45]$ & 0.015 & $0.1[46]$ & 11 & 0.0001 \\
\hline Proguanil & $306^{d}[47]$ & 1.2 & $0.25[39]$ & 13 & 0.02 \\
\hline Pyrimethamine & $281^{e}[48]$ & 1.1 & $0.06[49]$ & 1.6 & 0.04 \\
\hline Quinine & $11430^{f}[50]$ & 35 & $0.11^{9}[36]$ & 3.4 & 1.1 \\
\hline
\end{tabular}

a (Geometric) mean or median maximum plasma concentrations as determined in in vivo pharmacokinetic studies

b $\mathrm{DDI}$ index calculated by dividing the unbound $C_{\max }$ by the $I C_{50}$ concentration. $A$ DDI index cut-off value $\geq 0.1$ is believed to indicate the requirement for future in vivo pharmacokinetic studies [18]

c In Ugandan children aged 5-13 years with uncomplicated malaria

d In Thai children with uncomplicated multidrug-resistant falciparum malaria

e In patients with acute falciparum malaria

${ }^{f}$ In adult patients with uncomplicated falciparum malaria

9 In Thai patients with falciparum malaria 


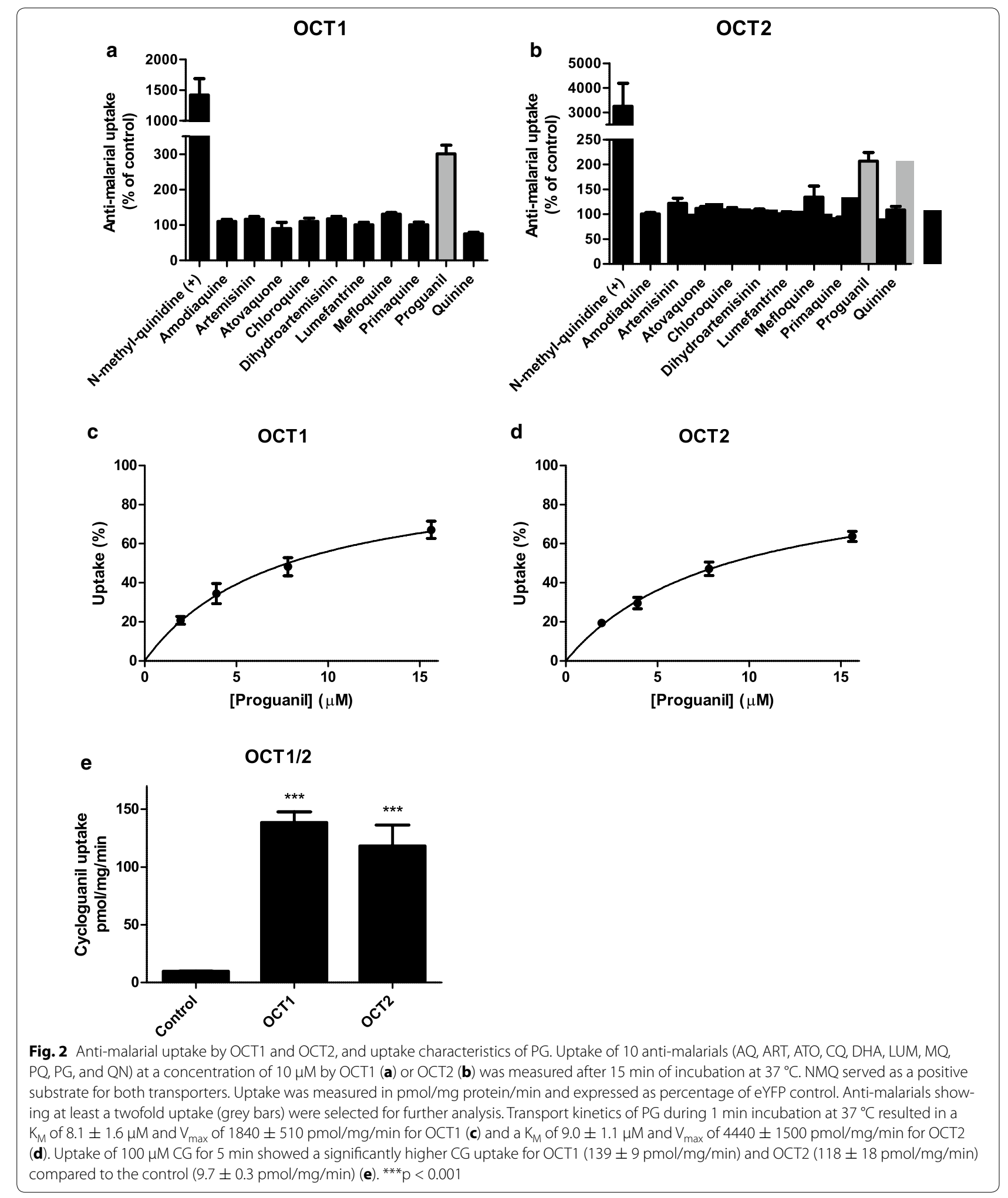




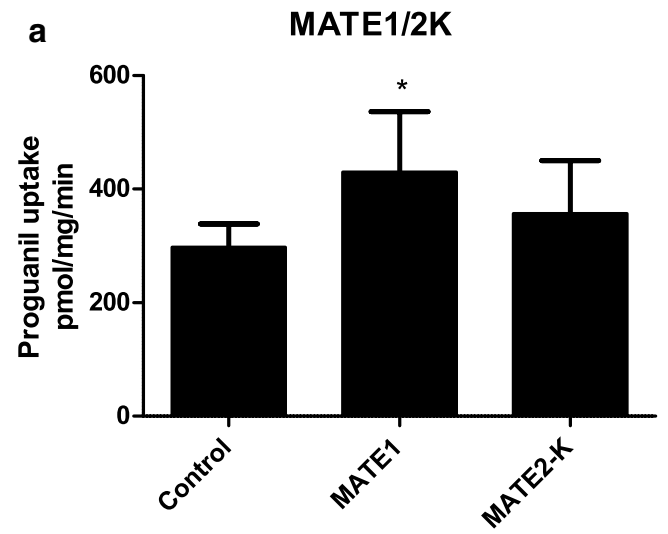

b OCT1/MATE1/2K

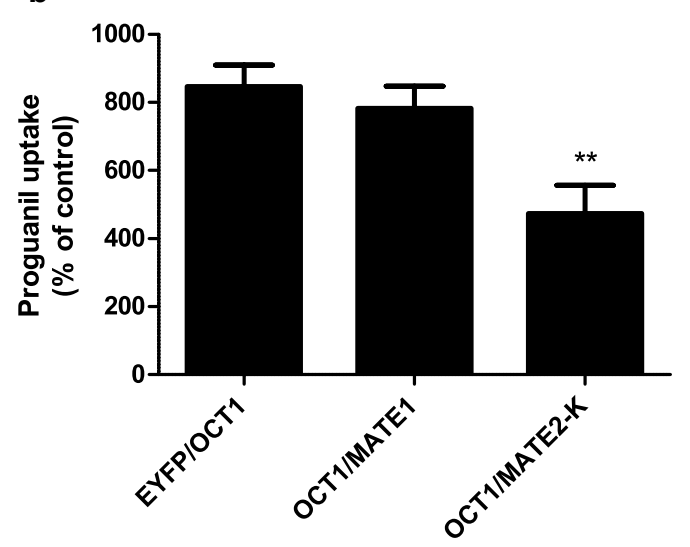

c

MATE1/2K

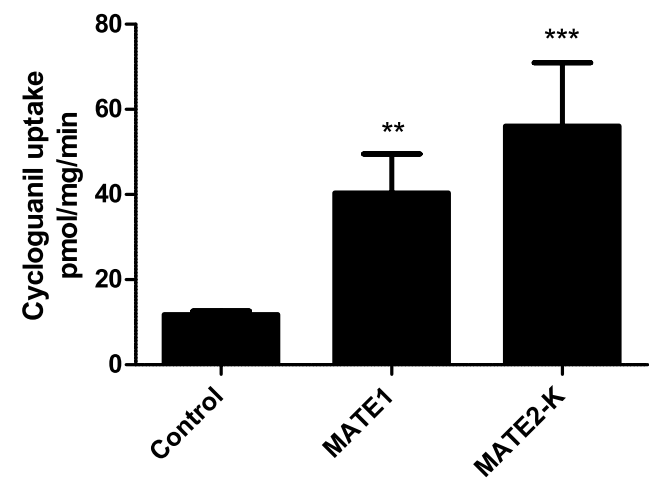

Fig. 3 PG and CG uptake by MATE1 and MATE2-K. Uptake of $100 \mu \mathrm{M}$ PG for $5 \mathrm{~min}$ for MATE1 (430 $\pm 110 \mathrm{pmol} / \mathrm{mg} / \mathrm{min}$ ) and MATE2-K (360 $\pm 90 \mathrm{pmol} / \mathrm{mg} / \mathrm{min}$ ) compared to the control (300 $\pm 40 \mathrm{pmol} /$ $\mathrm{mg} / \mathrm{min}$ ) in HEK293 transduced cells (a). Following co-transduction of eYFP and OCT1, after measuring uptake of 1 MM PG during 1 min incubation, PG was taken up for $850 \pm 60 \%$ as compared to eYFP control cells. MATE1 was not capable of reducing OCT1-mediated PG uptake by exporting this anti-malarial, however, MATE2-K reduced PG uptake to $470 \pm 80 \%$ of control, which is a relative decrease of $44 \%$ in uptake (b). Uptake of $100 \mu \mathrm{M}$ CG for 5 min was significantly higher for MATE1 (40 $\pm 9 \mathrm{pmol} / \mathrm{mg} / \mathrm{min}$ ) and MATE2-K (56 $\pm 15 \mathrm{pmol} / \mathrm{mg} / \mathrm{min}$ ) compared to the control (11.8 $\pm 0.9 \mathrm{pmol} / \mathrm{mg} / \mathrm{min})(\mathbf{c}) .{ }^{*} \mathrm{p}<0.05$, ${ }^{* *} p<0.01,{ }^{* * *} p<0.001$ and OCT1, OCT1 and MATE1, or OCT1 and MATE2$\mathrm{K}$. Uptake was represented as percentage of eYFP control cells. Incubation of $1 \mu \mathrm{M}$ PG for 1 min resulted in eightfold uptake by OCT1 ( $850 \pm 60 \%$ of control) (Fig. 3b). This uptake was similar in cells expressing OCT1 and MATE1 (780 $\pm 70 \%$ of control) simultaneously. However, uptake was significantly reduced in cells expressing OCT1 and MATE2-K $(470 \pm 80 \%$ of control, $\mathrm{p}<0.01)$, indicating that approximately $50 \%$ of PG was exported by MATE2-K as compared to eYFP/OCT1 transduced cells.

Finally, CG was analysed as a potential MATE1 and MATE2-K substrate by transfecting HEK293 cells with these transporters. Incubation of $100 \mu \mathrm{M}$ CG for $5 \mathrm{~min}$ resulted in significant uptake by MATE1 (40 $\pm 9 \mathrm{pmol} /$ $\mathrm{mg} / \mathrm{min})$ and MATE2-K (56 $\pm 15 \mathrm{pmol} / \mathrm{mg} / \mathrm{min}) \mathrm{com}$ pared to control cells $(11.8 \pm 0.9 \mathrm{pmol} / \mathrm{mg} / \mathrm{min})$ (Fig. 3c). This highlights the involvement of MATE1 and MATE2$\mathrm{K}$ in excretion of PG and its metabolite CG.

\section{Discussion}

In this study, the focus was on the interaction of antimalarial drugs with the organic cation transporters OCT1, OCT2, MATE1 and MATE2-K. In vitro, OCT1 activity was not affected by any of the tested anti-malarials, while OCT2 was inhibited in the low micromolar range by $A Q, P G, P Y R$ and QN. These compounds all share structural features with other OCT2 inhibitors as predicted previously [21].

Inhibition of OCT2 by AQ and PG has not been reported previously. The calculated DDI indices of both drugs were below 0.1 , indicating that clinically relevant DDIs related to OCT1 and OCT2 transport are unlikely to occur, but should not be fully excluded as local concentrations at the site of the transporter might be higher compared to systemic levels. Although it has been shown that co-administration of efavirenz (EFV), lopinavir (LPV)/ritonavir (RTV) or atazanavir/RTV with ATO/ PG cause a reduction in the AUC of both anti-malarials [4], the decrease in PG level was attributed to induction of CYP2C19 by EFV and LPV/RTV [23, 24]. In contrast, EFV has been shown to increase $C_{\max }$ levels of PG by $47 \%$, most likely caused by inhibition instead of induction of CYP2C19 metabolism, which was supported by a reduction in cycloguanil (CG) levels [5]. Another explanation for an increase in PG plasma concentration might be that EFV was also shown to be an inhibitor (absolute $\mathrm{IC}_{50}$ of $22 \mu \mathrm{M}$ ) of OCT1 [25] and it was demonstrated that PG is a substrate of OCT1. However, although maximum plasma concentrations of EFV reach $13 \mu \mathrm{M}$ [26], only about $0.22 \%$ is unbound $(0.03 \mu \mathrm{M})$ [27], resulting in a DDI index for OCT1 well below 0.1 , which makes an increase in the $\mathrm{C}_{\max }$ of PG unlikely. The AUC of EFV has been shown to increase in two subjects in a 
pharmacokinetic study upon simultaneous $A Q /$ artesunate treatment, resulting in increased hepatic transaminase levels [28]. Although we demonstrated that AQ inhibits OCT2, the calculated DDI index is very low. Hence, boosted EFV levels involving this transporter (and assuming that EFV is an OCT2 substrate) are highly unlikely.

PYR was shown to be the strongest inhibitor of OCT2 activity with an $\mathrm{IC}_{50}$ of $1.6 \mu \mathrm{M}$. Previously, PYR has been shown to reduce OCT2 activity by $60 \%$ at a concentration of $50 \mu \mathrm{M}$ [29]. This is a substantial difference with the presented findings, but could be explained by differences in cell type (HEK293 vs. HeLa) and substrate (concentration) [ASP vs. metformin (MET)] used. Results from another group, studying inhibition of MET elimination by PYR [30], were more in accordance with ours. Using HEK293 cells stably expressing human OCT2, a $\mathrm{K}_{\mathrm{i}}$ value of $10 \mu \mathrm{M}$ PYR for OCT2-mediated MET uptake was found. Although PYR was capable of increasing MET AUC at therapeutic dose, this effect was attributed to inhibition of MATE1 and MATE2-K, as their $K_{i}$ values were over 100-fold lower than the $K_{i}$ value for OCT2 inhibition [30].

In a previous study with stably transfected OCT1 and OCT2 HEK293 cells, inhibition of $N$-[methyl- $\left.{ }^{3} \mathrm{H}\right] 4$-phenylpyridinium $\left(\left[{ }^{3} \mathrm{H}\right] \mathrm{MPP}^{+}\right)$uptake by $\mathrm{QN}$ resulted in $\mathrm{IC}_{50}$ concentrations of 13 and $23 \mu \mathrm{M}$ for OCT1 and OCT2, respectively [31]. While QN was found to be more potent at inhibiting OCT1 [31], in this study QN was a more potent inhibitor of OCT2, which might be explained by a different choice of substrate. The presented results more closely resemble two other studies, that also used ASP as a substrate, and found that $20 \mu \mathrm{M}$ QN inhibited OCT2 by $72 \%$ [21] and $100 \mu \mathrm{M}$ QN inhibited OCT1 by $60 \%$ [20]. In the current study, the highest reported DDI index was 1.1 for QN. While DDIs for QN have been described, and a potential role at the transport level by P-glycoprotein/ABCB1 inhibition was studied previously [11], until now clinically relevant interactions caused by QN inhibition of OCT2 have not been reported. A pharmacokinetic study showed that concurrent administration with RTV resulted in a modest increase of $C_{\max }$ and AUC of QN [32]. Since RTV is not an OCT2 substrate [33], a transporter interaction with QN is unlikely. Inhibition of CYP2D6 by QN was speculated to cause this effect. In addition, simultaneous RTV and QN administration resulted in an approximately fourfold increase in $\mathrm{C}_{\max }$ and AUC of QN, which might be due to CYP3A4 interactions [32].

The DDI indices reported here should be interpreted with caution, as multiple factors may influence this value. Firstly, individual peak plasma concentrations in a different population may be substantially higher than the (geometric) mean or median shown in Table 2. Furthermore, the unbound fraction of a drug may alter depending on, e.g. plasma $\mathrm{pH}$ [34], pregnancy [35] and disease status. Indeed, in the case of QN treatment, increased intensity of malaria infection correlated with more plasma protein binding (lower unbound fraction) of QN [36, 37]. Still, as QN blood concentration rises with severity of disease [38], unbound QN concentrations may remain at a similar level due to a higher plasma protein binding [37].

PG was found to be the only anti-malarial substrate of OCT1 and OCT2, having similar $K_{M}$ values of 8.1 and $9.0 \mu \mathrm{M}$ for both transporters, respectively. This highlights OCT1 as a likely liver uptake transporter for PG, where it is metabolized into its active metabolite CG (Fig. 4). Moreover, OCT2 seems to be involved in the extrusion of PG via the kidneys, where it is excreted into the urine for $<40 \%$ as well as its metabolites [39]. Similarly, CG also was shown to be a substrate of both OCT1 and OCT2, which requires further investigation. The latter transporter seems to be involved in the renal elimination of CG as this compound can also be excreted into the urine [40].

In addition, when MATE1 and MATE2-K were transduced in HEK293 cells this resulted in a small significant uptake of PG by MATE1. When CG was used as potential substrate, uptake by MATE1 and MATE2-K was clearly present. Furthermore, in order to study the ability of MATE1 and MATE2-K to efflux PG, co-transduction studies were performed. When MATE1 and MATE2-K were co-transduced with OCT1, only MATE2-K reduced the intracellular PG concentration to $56 \%$ of its initial value indicating export of PG by this transporter. Thus, both CG and PG are most likely substrates of MATE1 and MATE2-K, who secrete these compounds from the proximal tubule into urine. Interestingly, PG shows structural similarity to MET (both contain guanidine fragments), a known MATE1 [41], MATE2-K [41], OCT1 [42], and OCT2 [43] substrate. It has been shown that polymorphisms in OCT1 can cause reduced liver uptake of MET [44], hence, these variants might also result in reduced hepatic PG uptake leading to less CG conversion. Additionally, as MET is the first-line drug of choice to treat type 2 diabetes (DMII), adverse drug interactions with PG may be anticipated, e.g. when the latter compound is used as prophylactic drug in travelers with DMII.

\section{Conclusion}

In the present study, the interaction of parent compounds with transport proteins was investigated. As part of these anti-malarials undergo biotransformation in the body, their metabolites might also influence transport activity. Therefore, future research should focus on these 


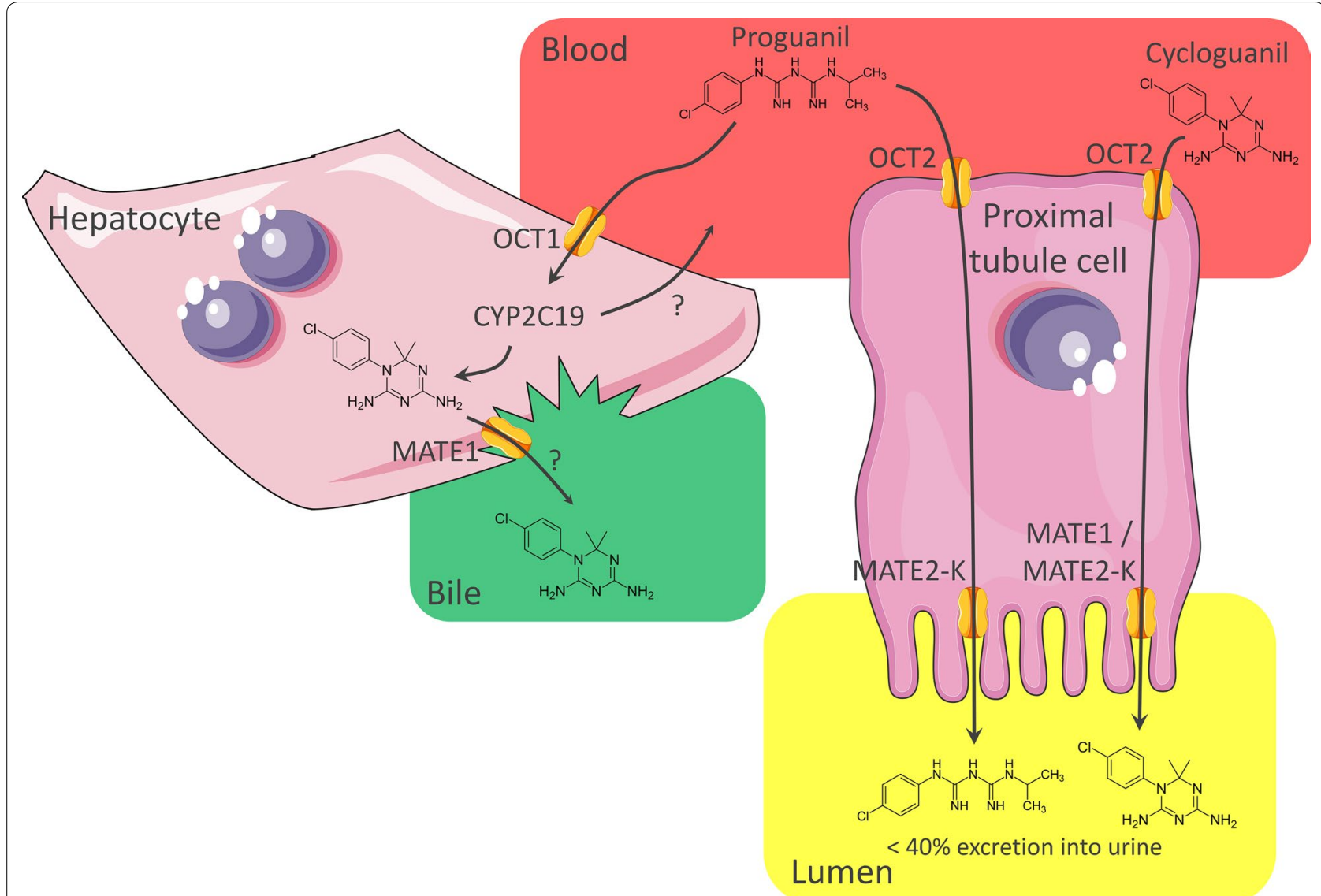

Fig. 4 Schematic of proguanil transport and metabolism. Our results suggest PG as substrate of OCT1, which is probably involved in uptake of this compound into hepatocytes, where it is converted to its active metabolite CG by CYP2C19 [22]. We further showed that PG is a substrate of the proximal tubule transporter OCT2 and MATE2-K, which might contribute to the excretion of $<40 \%$ unchanged PG into the urine [39]. In addition, CG was suggested to be a substrate of OCT1, OCT2, MATE1, and MATE2-K

products as they might increase the DDI potential of their parent compound or have different targets that may cause separate DDIs.

In conclusion, anti-malarials can reduce OCT1 and OCT2 transport activity in vitro. Only QN inhibited OCT2 at a therapeutic relevant dose with a DDI index above the 0.1 cut-off value, warranting in vivo pharmacokinetic studies. However, many factors influence this value and, therefore, individual cases of DDI with other tested compounds cannot be excluded. While anti-malarials and anti-retrovirals are often used concomitantly and may cause adverse DDIs, they most likely are not resulting from interactions with transporters described here due to differential substrate specificity for anti-retrovirals or low DDI indices. Furthermore, CG and PG were found to be substrates of OCT1, OCT2, MATE1 and MATE2$\mathrm{K}$, highlighting the importance of these transporters in CG and PG distribution and excretion. As PG shares substrate overlap with MET for OCT1, OCT2, MATE1 and
MATE2-K, DDIs can be anticipated during concurrent treatment.

\section{Authors' contributions}

MvdV, RWS, FGMR, and JBK conceived the study. All authors participated in the design of the study. MvdV, JJMWvdH, SRR, EGEH designed and performed the transport assays. AB performed and analysed the LC-MS/MS assays. MvdV wrote the first draft of the manuscript. All authors read and approved the final manuscript.

\section{Author details}

${ }^{1}$ Department of Pharmacology and Toxicology, Radboud University Medical Center, Geert Grooteplein 28, 6525 GA Nijmegen, The Netherlands. ${ }^{2}$ Department of Medical Microbiology, Radboud University Medical Center, Geert Grooteplein 28, 6525 GA Nijmegen, The Netherlands.

\section{Acknowledgements}

Not applicable.

\section{Competing interests}

The authors declare that they have no competing interests.

\section{Availability of data and materials}

Not applicable. 


\section{Consent for publication}

Not applicable.

\section{Ethics approval and consent to participate}

Not applicable.

\section{Funding}

Maarten van der Velden was supported by a Radboud University Medical Center personal grant.

\section{Publisher's Note}

Springer Nature remains neutral with regard to jurisdictional claims in published maps and institutional affiliations.

Received: 8 May 2017 Accepted: 11 October 2017

Published online: 23 October 2017

\section{References}

1. WHO. Malaria fact sheet no. 94. Geneva: World Health Organization; 2015.

2. WHO. Guidelines for the treatment of malaria. 3rd ed. Geneva: World Health Organization; 2015.

3. Khoo S, Back D, Winstanley P. The potential for interactions between antimalarial and antiretroviral drugs. AIDS. 2005;19:995-1005.

4. van Luin M, Van der Ende ME, Richter C, Visser M, Faraj D, Van der Ven A, et al. Lower atovaquone/proguanil concentrations in patients taking efavirenz, lopinavir/ritonavir or atazanavir/ritonavir. AIDS. 2010;24:1223-6.

5. Soyinka JO, Onyeji CO. Alteration of pharmacokinetics of proguanil in healthy volunteers following concurrent administration of efavirenz. Eur J Pharm Sci. 2010;39:213-8.

6. German P, Parikh S, Lawrence J, Dorsey G, Rosenthal PJ, Havlir D, et al. Lopinavir/ritonavir affects pharmacokinetic exposure of artemether/ lumefantrine in HIV-uninfected healthy volunteers. J Acquir Immune Defic Syndr. 2009;51:424-9.

7. Sousa M, Pozniak A, Boffito M. Pharmacokinetics and pharmacodynamics of drug interactions involving rifampicin, rifabutin and antimalarial drugs. J Antimicrob Chemother. 2008;62:872-8

8. Wanwimolruk S, Kang W, Coville PF, Viriyayudhakorn S, Thitiarchakul S. Marked enhancement by rifampicin and lack of effect of isoniazid on the elimination of quinine in man. Br J Clin Pharmacol. 1995;40:87-91.

9. Bibi Z. Role of cytochrome P450 in drug interactions. Nutr Metab (Lond). 2008;5:27

10. Muller F, Fromm MF. Transporter-mediated drug-drug interactions. Pharmacogenomics. 2011;12:1017-37.

11. Rijpma SR, van den Heuvel JJ, van der Velden M, Sauerwein RW, Russe FG, Koenderink JB. Atovaquone and quinine anti-malarials inhibit ATP binding cassette transporter activity. Malar J. 2014;13:359.

12. Gorboulev V, Ulzheimer JC, Akhoundova A, Ulzheimer-Teuber I, Karbach U, Quester S, et al. Cloning and characterization of two human polyspecific organic cation transporters. DNA Cell Biol. 1997;16:871-81.

13. Nies AT, Herrmann E, Brom M, Keppler D. Vectorial transport of the plant alkaloid berberine by double-transfected cells expressing the human organic cation transporter 1 (OCT1, SLC22A1) and the efflux pump MDR1 P-glycoprotein (ABCB1). Naunyn Schmiedebergs Arch Pharmacol. 2008;376:449-61.

14. Motohashi H, Sakurai Y, Saito H, Masuda S, Urakami Y, Goto M, et al. Gene expression levels and immunolocalization of organic ion transporters in the human kidney. J Am Soc Nephrol. 2002:13:866-74.

15. Otsuka M, Matsumoto T, Morimoto R, Arioka S, Omote H, Moriyama Y. A human transporter protein that mediates the final excretion step for toxic organic cations. Proc Natl Acad Sci USA. 2005;102:17923-8.

16. Masuda S, Terada T, Yonezawa A, Tanihara Y, Kishimoto K, Katsura T, et al. Identification and functional characterization of a new human kidneyspecific $\mathrm{H}+$ /organic cation antiporter, kidney-specific multidrug and toxin extrusion 2. J Am Soc Nephrol. 2006;17:2127-35.

17. Gorman CM, Howard BH, Reeves R. Expression of recombinant plasmids in mammalian cells is enhanced by sodium butyrate. Nucleic Acids Res. $1983 ; 11: 7631-48$
18. International-Transporter-Consortium, Giacomini KM, Huang SM, Tweedie DJ, Benet LZ, Brouwer KL, et al. Membrane transporters in drug development. Nat Rev Drug Discov. 2010;9:215-36.

19. van Montfoort JE, Muller M, Groothuis GM, Meijer DK, Koepsell H, Meier PJ. Comparison of "type I" and "type II" organic cation transport by organic cation transporters and organic anion-transporting polypeptides. J Pharmacol Exp Ther. 2001;298:110-5.

20. Ahlin G, Karlsson J, Pedersen JM, Gustavsson L, Larsson R, Matsson P, et al. Structural requirements for drug inhibition of the liver specific human organic cation transport protein 1. J Med Chem. 2008;51:5932-42.

21. Kido Y, Matsson P, Giacomini KM. Profiling of a prescription drug library for potential renal drug-drug interactions mediated by the organic cation transporter 2. J Med Chem. 2011;54:4548-58.

22. Funck-Brentano C, Becquemont L, Lenevu A, Roux A, Jaillon P, Beaune P. Inhibition by omeprazole of proguanil metabolism: mechanism of the interaction in vitro and prediction of in vivo results from the in vitro experiments. J Pharmacol Exp Ther. 1997;280:730-8.

23. Yeh RF, Gaver VE, Patterson KB, Rezk NL, Baxter-Meheux F, Blake MJ, et al. Lopinavir/ritonavir induces the hepatic activity of cytochrome P450 enzymes CYP2C9, CYP2C19, and CYP1A2 but inhibits the hepatic and intestinal activity of CYP3A as measured by a phenotyping drug cocktail in healthy volunteers. J Acquir Immune Defic Syndr. 2006:42:52-60.

24. Damle B, LaBadie R, Crownover P, Glue P. Pharmacokinetic interactions of efavirenz and voriconazole in healthy volunteers. Br J Clin Pharmacol. 2008;65:523-30.

25. Moss DM, Liptrott NJ, Siccardi M, Owen A. Interactions of antiretroviral drugs with the SLC22A1 (OCT1) drug transporter. Front Pharmacol. 2015;6:78.

26. Villani P, Regazzi MB, Castelli F, Viale P, Torti C, Seminari E, Maserati R. Pharmacokinetics of efavirenz (EFV) alone and in combination therapy with nelfinavir (NFV) in HIV-1 infected patients. Br J Clin Pharmacol. 1999;48:712-5

27. Avery LB, Sacktor N, McArthur JC, Hendrix CW. Protein-free efavirenz concentrations in cerebrospinal fluid and blood plasma are equivalent: applying the law of mass action to predict protein-free drug concentration. Antimicrob Agents Chemother. 2013;57:1409-14.

28. German P, Greenhouse B, Coates C, Dorsey G, Rosenthal PJ, Charlebois $E$, et al. Hepatotoxicity due to a drug interaction between amodiaquine plus artesunate and efavirenz. Clin Infect Dis. 2007;44:889-91.

29. Meyer zu Schwabedissen HE, Verstuyft C, Kroemer HK, Becquemont L, Kim RB. Human multidrug and toxin extrusion 1 (MATE1/SLC47A1) transporter: functional characterization, interaction with OCT2 (SLC22A2), and single nucleotide polymorphisms. Am J Physiol Renal Physiol. 2010;298:F997-1005

30. Kusuhara H, Ito S, Kumagai Y, Jiang M, Shiroshita T, Moriyama Y, et al. Effects of a MATE protein inhibitor, pyrimethamine, on the renal elimination of metformin at oral microdose and at therapeutic dose in healthy subjects. Clin Pharmacol Ther. 2011:89:837-44.

31. Muller J, Lips KS, Metzner L, Neubert RH, Koepsell H, Brandsch M. Drug specificity and intestinal membrane localization of human organic cation transporters (OCT). Biochem Pharmacol. 2005:70:1851-60.

32. Soyinka JO, Onyeji CO, Omoruyi SI, Owolabi AR, Sarma PV, Cook JM. Pharmacokinetic interactions between ritonavir and quinine in healthy volunteers following concurrent administration. $\mathrm{Br} J$ Clin Pharmacol. 2010;69:262-70.

33. Jung $N$, Lehmann C, Rubbert A, Knispel M, Hartmann P, van Lunzen J, et al. Relevance of the organic cation transporters 1 and 2 for antiretroviral drug therapy in human immunodeficiency virus infection. Drug Metab Dispos. 2008:36:1616-23.

34. Hinderling $\mathrm{PH}$, Hartmann D. The $\mathrm{pH}$ dependency of the binding of drugs to plasma proteins in man. Ther Drug Monit. 2005;27:71-85.

35. Perucca E, Crema A. Plasma protein binding of drugs in pregnancy. Clin Pharmacokinet. 1982;7:336-52.

36. Wanwimolruk S, Denton JR. Plasma protein binding of quinine: binding to human serum albumin, alpha 1-acid glycoprotein and plasma from patients with malaria. J Pharm Pharmacol. 1992;44:806-11.

37. Silamut K, Molunto P, Ho M, Davis TM, White NJ. Alpha 1-acid glycoprotein (orosomucoid) and plasma protein binding of quinine in falciparum malaria. Br J Clin Pharmacol. 1991;32:311-5. 
38. White NJ, Looareesuwan S, Warrell DA, Warrell MJ, Bunnag D, Harinasuta T. Quinine pharmacokinetics and toxicity in cerebral and uncomplicated Falciparum malaria. Am J Med. 1982;73:564-72.

39. GlaxoSmithKline Inc. Malarone. GSK Product Monograph. Research Triangle Park, NC, GSK. 2004.

40. Somogyi AA, Reinhard HA, Bochner F. Pharmacokinetic evaluation of proguanil: a probe phenotyping drug for the mephenytoin hydroxylase polymorphism. Br J Clin Pharmacol. 1996;41:175-9.

41. Tanihara Y, Masuda S, Sato T, Katsura T, Ogawa O, Inui K. Substrate specificity of MATE1 and MATE2-K, human multidrug and toxin extrusions/ $\mathrm{H}(+)$-organic cation antiporters. Biochem Pharmacol. 2007:74:359-71.

42. Kimura N, Masuda S, Tanihara Y, Ueo H, Okuda M, Katsura T, Inui K. Metformin is a superior substrate for renal organic cation transporter OCT2 rather than hepatic OCT1. Drug Metab Pharmacokinet. 2005;20:379-86.

43. Kimura N, Okuda M, Inui K. Metformin transport by renal basolateral organic cation transporter hOCT2. Pharm Res. 2005;22:255-9.

44. Shu Y, Sheardown SA, Brown C, Owen RP, Zhang S, Castro RA, et al. Effect of genetic variation in the organic cation transporter 1 (OCT1) on metformin action. J Clin Investig. 2007;117:1422-31.
45. Mwesigwa J, Parikh S, McGee B, German P, Drysdale T, Kalyango JN, et al Pharmacokinetics of artemether-lumefantrine and artesunate-amodiaquine in children in Kampala, Uganda. Antimicrob Agents Chemother. 2010:54:52-9.

46. Giao PT, de Vries PJ. Pharmacokinetic interactions of antimalarial agents. Clin Pharmacokinet. 2001;40:343-73.

47. Sabchareon A, Attanath P, Phanuaksook P, Chanthavanich P, Poonpanich $Y$, Mookmanee D, et al. Efficacy and pharmacokinetics of atovaquone and proguanil in children with multidrug-resistant Plasmodium falciparum malaria. Trans R Soc Trop Med Hyg. 1998;92:201-6.

48. Barnes Kl, Little F, Smith PJ, Evans A, Watkins WM, White NJ. Sulfadoxinepyrimethamine pharmacokinetics in malaria: pediatric dosing implications. Clin Pharmacol Ther. 2006;80:582-96.

49. Rudy AC, Poynor WJ. Binding of pyrimethamine to human plasma proteins and erythrocytes. Pharm Res. 1990;7:1055-60.

50. Pukrittayakamee S, Wanwimolruk S, Stepniewska K, Jantra A, Huyakorn S, Looareesuwan S, White NJ. Quinine pharmacokinetic-pharmacodynamic relationships in uncomplicated Falciparum malaria. Antimicrob Agents Chemother. 2003;47:3458-63.

\section{Submit your next manuscript to BioMed Central and we will help you at every step:}

- We accept pre-submission inquiries

- Our selector tool helps you to find the most relevant journal

- We provide round the clock customer support

- Convenient online submission

- Thorough peer review

- Inclusion in PubMed and all major indexing services

- Maximum visibility for your research

Submit your manuscript at www.biomedcentral com/submit 